\title{
Optimizing care for critically ill older adults
}

\author{
Olivia Geen MD, Bram Rochwerg MD MSc, Xuyi Mimi Wang MD MMEd
}

Cite as: CMAJ 2021 October 4;193:E1525-33. doi: 10.1503/cmaj.210652

A s populations age worldwide, and medical advances enable a high quality of life into the eighth, ninth and even tenth decades of life, there have been increased admissions to intensive care units (ICUs) among adults aged 65 years and older (older adults). Older adults now account for more than $50 \%$ of patients in ICUs in Canada. ${ }^{1}$ To date, during the COVID-19 pandemic, $59.3 \%$ of patients with COVID-19 admitted to ICUs in Canada were older than 60 years. ${ }^{2}$ People requiring ICU admission are deemed "critically ill." Critically ill older adults are a unique population with distinct care requirements owing to physiologic and pathologic changes associated with aging. We review best practice in the care of critically ill older adults, drawing on available evidence (see Box 1). We discuss integration of evidence-based geriatric principles into ICU care, the importance of identifying pre-existing frailty in older adults, measures to prevent and treat delirium, and optimization of post-ICU care.

\section{Why and how should evidence-based geriatric principles be integrated into routine ICU care?}

Because older adults are more likely to have complex medical and social needs, it is important to use a holistic and comprehensive approach to their care in all health care settings. The increasing numbers of older adults requiring ICU care has led to the development of the nascent field of geriatric critical care. Practitioners of geriatric medicine have expertise in caring for frail older adults, and there is growing interest within the critical care community in adopting evidence-based geriatric principles in the ICU. ${ }^{3-11}$ Geriatricians are already involved in successful collaborative models with clinicians who have expertise in orthopedics, cardiology, vascular surgery, trauma and oncology, with evidence for improved patient outcomes. ${ }^{10,12-15}$ However, an

\section{Box 1: Literature search}

We conducted a targeted, nonsystematic MEDLINE (1946-February 2020) search using the terms "geriatrics" and "critical care," or "intensive care." The search was limited to articles in English. There were no restrictions on study type, but we primarily sought relevant randomized controlled trials, systematic reviews and meta-analyses. Relevant studies were selected, and their references manually searched for additional papers. Most studies were observational.

\section{Key points}

- The integration of geriatric principles into routine care in the intensive care unit (ICU) should be considered as part of the comprehensive care of all older adults.

- Frailty is independently associated with a higher risk of dying in the ICU and should be identified early in admission, using the Clinical Frailty Scale, based on clinical status at least 2 weeks before the acute illness.

- The ABCDEF bundle should be used to help with prevention and treatment of delirium in older adults admitted to the ICU.

- Post-intensive care syndrome includes new or worsening cognitive, physical or mental health deficits, which can persist after ICU discharge.

- Older ICU survivors may benefit from physical rehabilitation, the use of an ICU diary, and integration of geriatric principles into routine post-ICU care.

important barrier to collaborative care models in Canada is the relative scarcity of geriatricians, with fewer than 400 specialists nationally. It is thus most practical for principles used in comprehensive geriatric assessment to be incorporated in other ways into routine ICU care.

Integration of geriatric principles into routine care has been well studied in specialized acute care of the elderly (ACE) units for older adults in hospital who are acutely unwell but do not require ICU admission. In a systematic review and meta-analysis of 13 trials and 6839 patients with a mean age of 81 years, the use of geriatric principles in ACE units was shown to reduce hospital-acquired functional decline, falls, delirium, hospital length of stay, cost and discharge to long-term care. ${ }^{16}$ Table 1 summarizes the multicomponent interventions typically used in ACE units. Capacity-building collaborative care models to increase geriatric competencies among ICU staff, as well as innovative strategies such as abbreviated geriatric assessments using electronic health records, ${ }^{25}$ are promising areas for future research.

Comprehensive care is incomplete without consideration of patients' social contexts. Geriatricians use a biopsychosocial approach to care planning. Although current evidence is of very low to moderate quality, guidelines support increasing family presence, support and communication in the ICU. ${ }^{26}$ Resources to increase family-centred care are available online (https://www.sccm.org/ Research/Guidelines/Guidelines/Family-Centered-Care-in-the-ICU). 


\section{What is the relevance of pre-existing frailty for critically ill older adults?}

The prevalence of frailty in older patients admitted to the ICU is about 30\%, according to pooled results across 6 prospective observational studies. ${ }^{27}$ Frailty is a state of decreased physiologic, functional and cognitive reserve that results in increased vulnerability to new health stressors. ${ }^{28}$ It is believed to result from the interplay of comorbid diseases, genetics and environmental factors, ${ }^{29}$ and may be partially reversible in the intermediate stages. ${ }^{30}$ Frailty is not an inherent part of aging, although age is a risk factor for frailty and an independent risk factor for adverse outcomes. ${ }^{31}$

Ascertaining frailty is relevant in the ICU as part of a global assessment to better understand a patient's risk of adverse outcomes and to inform goals-of-care discussions. ${ }^{29,32-35}$ In a prospective multicentre cohort study of 610 patients older than 80 years in Canada, frailty was found to be a more significant independent predictor of long-term ICU outcomes than age, illness severity or comorbidity. ${ }^{36}$ A 2017 meta-analysis of 10 prospective cohort studies of moderate quality (mean NewcastleOttawa Scale score 6.5) found that pre-hospital frailty was associated with increased hospital mortality (relative risk [RR] $1.71,95 \%$ confidence interval $[\mathrm{Cl}] 1.43-2.05)$ and long-term mortality (RR $1.53,95 \% \mathrm{Cl} 1.40-1.68$ ), independent of age or illness severity. ${ }^{27}$ Several studies have reported an incremental increase in mortality for each additional point on the Clinical Frailty Scale (CFS), $27,33,37,38$ particularly in those with severe or very severe frailty (CFS $\geq 7$ ). ${ }^{31,38}$ Understanding the impact of frailty on ICU prognosis shifts the concern from a patient's age toward their overall clinical status and trajectory before ICU admission.

With respect to post-ICU morbidity, patients who are frail and survive their incident critical illness face worsened physical function and higher admission rates to long-term care homes compared with older adults who are not frail..27,37,39,40 A 15-year-long prospective longitudinal study of 754 community-dwelling adults

Table 1: Comprehensive multicomponent checklist for routine ICU care*

Principle

Routine practice suggestion

Prevention of delirium

Sleep

Cognition

Mood

Mobility and early

rehabilitation

Nutrition

Continence

Skin integrity

Minimization of

polypharmacy

Environmental modifications to facilitate physical and cognitive function

Early discharge planning
- Provide patients with hearing aids and glasses

- Implement ABCDEF bundle†

- Minimize use of restraints and tethers

- Earplugs, minimization of noise

- Conversion to daytime bolus feeds to decrease night-time interruptions $\dagger$

- Cognitive-stimulation activities such as music, family-voice reorientation and family involvement

- Screening for depressive symptoms in patients with prolonged ICU admissions, with referral to psychiatry as needed

- Not suggested to screen acutely unwell, newly admitted patients $\dagger$

- Early physiotherapy or occupational therapy assessment for advancing mobility and function toward maintenance of activities of daily living

- Dietitian consult

- Prompt correction of dehydration

- Removal of indwelling catheters to avoid catheter-associated bladder infections and promote mobility

- Maintenance of regular bowel movements

- Frequent turning to avoid pressure injuries

- Daily medication review by pharmacist using STOPP/START criteria ${ }^{17}$ or American Geriatrics Society Beers criteria ${ }^{18}$ of potentially inappropriate medications

- Monitor new high-risk medications (antipsychotics, sedative-hypnotics, opioids) with a plan to taper or discontinue while in ICU†

- Large clocks and calendars

- Handrails, uncluttered hallways to allow mobilization

- Elevated toilet seats and door levers (not knobs)

- Paint colours that emphasize earth tones with contrast between floor, wall and ceiling, to aid patients with impaired depth perception

- Early involvement of social worker and family

- Multidisciplinary team rounding with early ongoing emphasis on the goal of returning home (or to pre-hospital living environment)

Note: ACE = acute care of the elderly, ICU = intensive care unit, START = Screening Tool to Alert to Right Treatment, STOPP = Screening Tool of Older Persons' Prescriptions *Based on evidence-based principles of ACE unit care. ${ }^{19-23}$

†Not included in traditional ACE unit protocols. ABCDEF bundle is a multicomponent strategy for delirium prevention and treatment, and includes pain management, trials of spontaneous awakening, choice of analgesia and sedation, monitoring and management of delirium, early mobilization, and family engagement. ${ }^{24}$ 
older than 70 years found that patients who were pre-frail (1 or 2 Fried frailty criteria present, using the Fried phenotypic model of frailty) or frail (3 or more criteria) did not return to their baseline physical function by 6 months. ${ }^{39}$ They did, however, improve compared with their functional status 1 month after ICU discharge, when disability was at its greatest. ${ }^{39}$ In comparison, older adults who were not frail at ICU admission returned close to their baseline level of physical function by 6 months. ${ }^{39}$ Patients who were frail had a $58.8 \%$ admission rate to long-term care at 6 months, ${ }^{39}$ a finding consistent with a 2017 meta-analysis in which these patients were less likely to be discharged home ${ }^{27}$ (RR $0.59,95 \% \mathrm{Cl} 0.49-0.71$ ). When counselling patients and families on post-ICU expectations, explicit consideration of frailty helps prevent overestimation of functional impairment in those who are not frail, and underestimation in those who are frail (Figure 1). Nevertheless, it is not clear whether the post-ICU outcomes observed are inevitable for patients who are frail, as no studies have examined how changes to management during or after ICU admission could mitigate the incidence or worsening of frailtyassociated outcomes. This is an important area for future research.

The 2 main conceptual frameworks of frailty are a physical, or phenotypic, model ${ }^{41}$ and a deficit accumulation, or index, model. ${ }^{28}$ Several tools based on these frameworks may be used to assess frailty. ${ }^{42}$ For older adults admitted to the ICU, we favour the Clinical Frailty Scale presented in Figure 2. The CFS is highly correlated with the Frailty Index ${ }^{28}$ and has been validated with good inter-rater reliability ( $\kappa 0.74$ ) between assessors in the ICU setting. ${ }^{43-46}$ Its use is more feasible in critically ill patients than other commonly used tools that require grip strength or mobility assessments, for example. ${ }^{41,47}$ To avoid overscoring the CFS based on the state of critical illness of a patient in the ICU, the assessment should be based on clinical status at least 2 weeks before admission. ${ }^{48}$ If there is limited history available from the patient or family members to make this assessment, collateral information can be sought through community care providers, including personal support workers, pharmacists, family physicians and local community care coordinators. Clinicians unfamiliar with the CFS are encouraged to review resources on proper use to ensure reliability. ${ }^{48,49}$

\section{Why is recognizing delirium important?}

Delirium in the ICU is common, although underdiagnosed, with prevalence of $20 \%-84 \%$ depending on the severity of illness and method of diagnosis. ${ }^{50-55}$ It is defined by a change from baseline in attention and awareness that is acute, fluctuating and accompanied by disturbed cognition (memory deficit, disorientation, or abnormal language, visuospatial ability or perception). ${ }^{56}$

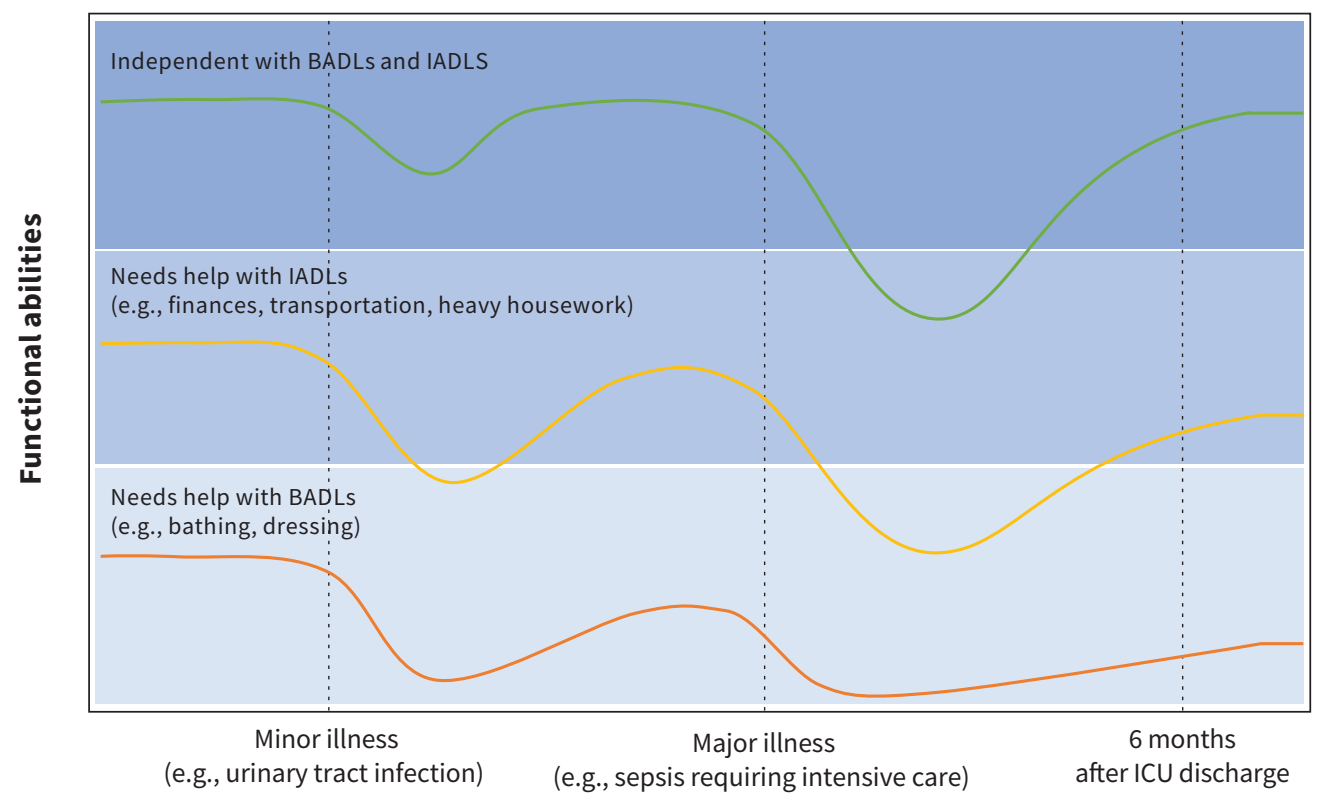

Time

Figure 1: Potential impact of pre-existing frailty on outcomes after minor and major illness. The green line represents the medical course of an individual who is not frail (Clinical Frailty Score [CFS] 1-3, independent with basic and instrumental activities of daily living [BADLs and IADLs]): a minor illness may cause a transient reduction in physical or cognitive function, but the individual recovers to baseline. A major illness requiring admission to intensive care may cause substantial reduction in function and impairment in ADLs, but a patient who is not frail may improve close to baseline by 6 months. The yellow line represents the medical course of an individual with mild frailty (CFS 4-5): a minor illness may cause a disproportionate reduction in function, and the individual may not return to baseline. A major illness requiring admission to intensive care may cause further substantial reduction in function, from which the individual recovers only partially by 6 months. The orange line represents the medical course of an individual with moderate to severe frailty (CFS 6-8): a minor illness is likely to cause further disproportionate reduction in already limited function without return to baseline, and a major illness is likely to result in substantial reduction in function that does not improve by 6 months, assuming the individual is able to survive the index critical illness (in-hospital mortality for CFS 8 is reported at $48 \%,{ }^{31}$ and 12 -month survival for CFS $6-7$ is $35 \%{ }^{37}$ ). Note: ICU = intensive care unit. 


\section{CLINICAL FRAILTY SCALE}

\begin{tabular}{|c|c|c|c|}
\hline & & $\begin{array}{l}\text { VERY } \\
\text { FIT }\end{array}$ & $\begin{array}{l}\text { People who are robust, active, energetic and motivated. } \\
\text { They tend to exercise regularly and are among the fittest } \\
\text { for their age. }\end{array}$ \\
\hline & & FIT & $\begin{array}{l}\text { People who have no active disease symptoms but are } \\
\text { less fit than category } 1 . \text { Often, they exercise or are very } \\
\text { active occasionally, e.g., seasonally. }\end{array}$ \\
\hline & & $\begin{array}{r}\text { MANAGING } \\
\text { WELL }\end{array}$ & $\begin{array}{l}\text { People whose medical problems are well controlled, even } \\
\text { if occasionally symptomatic, but often are not regularly active } \\
\text { beyond routine walking. }\end{array}$ \\
\hline & 4 & $\begin{array}{r}\text { LIVING } \\
\text { WITH } \\
\text { VERY MILD } \\
\text { FRAILTY }\end{array}$ & $\begin{array}{l}\text { Previously "vulnerable," this category marks early transition } \\
\text { from complete independence. While not dependent on } \\
\text { others for daily help, often symptoms limit activities. } \\
\text { A common complaint is being "slowed up" and/or being } \\
\text { tired during the day. }\end{array}$ \\
\hline & 5 & $\begin{array}{r}\text { LIVING } \\
\text { WITH } \\
\text { MILD } \\
\text { FRAILTY }\end{array}$ & $\begin{array}{l}\text { People who often have more evident slowing, and need help } \\
\text { with high order instrumental activities of daily living } \\
\text { (finances, transportation, heavy housework). Typically, } \\
\text { mild frailty progressively impairs shopping and walking } \\
\text { outside alone, meal preparation, medications and begins } \\
\text { to restrict light housework. }\end{array}$ \\
\hline & & $\begin{array}{r}\text { LIVING } \\
\text { WITH } \\
\text { MODERATE } \\
\text { FRAILTY }\end{array}$ & $\begin{array}{l}\text { People who need help with all outside activities and with } \\
\text { keeping house. Inside, they often have problems with } \\
\text { stairs and need help with bathing and might need minimal } \\
\text { assistance (cuing, standby) with dressing. }\end{array}$ \\
\hline & & $\begin{array}{l}\text { LIVING } \\
\text { WITH } \\
\text { SEVERE } \\
\text { FRAILTY }\end{array}$ & $\begin{array}{l}\text { Completely dependent for personal care, from whatever } \\
\text { cause (physical or cognitive). Even so, they seem stable } \\
\text { and not at high risk of dying (within } \sim 6 \text { months). }\end{array}$ \\
\hline & & $\begin{array}{l}\text { LIVING } \\
\text { WITH VERY } \\
\text { SEVERE } \\
\text { FRAILTY }\end{array}$ & $\begin{array}{l}\text { Completely dependent for personal care and approaching } \\
\text { end of life. Typically, they could not recover even from a } \\
\text { minor illness. }\end{array}$ \\
\hline & 9 & $\begin{array}{r}\text { TERMINALLY } \\
\text { ILL }\end{array}$ & $\begin{array}{l}\text { Approaching the end of life. This category applies to people } \\
\text { with a life expectancy }<6 \text { months, who are not otherwise } \\
\text { living with severe frailty. (Many terminally ill people can still } \\
\text { exercise until very close to death.) }\end{array}$ \\
\hline
\end{tabular}

\section{SCORING FRAILTY IN PEOPLE WITH DEMENTIA}

The degree of frailty generally corresponds to the degree of dementia. Common symptoms in mild dementia include forgetting the details of a recent event, though still remembering the event itself, repeating the same question/story and social withdrawal.
In moderate dementia, recent memory is very impaired, even though they seemingly can remember their past life events well. They can do personal care with prompting.

In severe dementia , they cannot do personal care without help.

In very severe dementia they are often bedfast. Many are virtually mute.

Clinical Frailty Scale @2005-2020 Rockwood, Version 2.0 (EN).

All rights reserved. For permission: www.geriatricmedicineresearch.ca

Rockwood $\mathrm{K}$ et al. A global clinical measure of fitness and frailty in elderly people.

CMAJ 2005;173:489-495.

Figure 2: The Clinical Frailty Score (CFS) can be used to summarize the overall clinical status of a patient based on comorbidities, activity level and functional impairment. Through conversations with the patient, family or other reliable informant, clinical judgment is used to determine which category best fits the patient. It is recommended that the score be based on the patient's status 2 weeks before admission to an intensive care unit (ICU) (reproduced with permission: Rockwood et al. ${ }^{28}$ ). 
A 2015 meta-analysis found that delirium in the ICU was associated with increased mortality (RR 2.19, 95\% Cl 1.78-2.70), a finding that persisted even after the metaregression to account for age, proportion of female participants and Acute Physiology and Chronic Health Evaluation II (APACHE II) scores; longer duration of mechanical ventilation (mean difference [MD] 1.79 days longer), longer ICU admission (MD 33 hours longer), longer hospital stay (MD 23.3 hours longer) and postdischarge cognitive impairment at 3 and 12 months, compared with those who do not develop delirium. ${ }^{51}$

Risk factors for delirium in the ICU include benzodiazepine use, blood transfusions, increasing age, a history of dementia, previous coma, higher APACHE II and American Society of Anesthesiology scores, and pre-ICU emergency surgery or trauma. ${ }^{57}$ Of these, benzodiazepine use is potentially modifiable $;^{58,59}$ this class of medication should be avoided unless clearly indicated for a specific medical condition, such as acute alcohol withdrawal.

\section{How can delirium be prevented and managed?}

Because delirium often goes undiagnosed, it is important to optimize recognition of the condition. The 2018 Clinical Practice Guidelines for ICU Pain, Agitation/Sedation, Delirium, Immobility and Sleep Disruption (PADIS) recommend screening for delirium with a valid tool, ${ }^{57}$ such as the Confusion Assessment method for the ICU (CAM-ICU) ${ }^{60}$ or Intensive Care Delirium Screening Checklist (ICDSC). ${ }^{61}$ The ICDSC has a sensitivity of $99 \%$ and specificity of $64 \%,{ }^{61}$ and the CAM-ICU has a sensitivity of $75.5 \%$ and specificity of $95.8 \% .^{60}$

Nonpharmacologic interventions are the mainstay of preventing delirium in the ICU. A meta-analysis of 9 studies found that earplugs reduce the incidence of delirium (RR $0.59,95 \% \mathrm{Cl}$ $0.44-0.78),{ }^{62}$ suggesting their use is reasonable as a low-harm, low-cost intervention. Several small randomized controlled trials (RCTs) of limited generalizability have investigated other single-component interventions with negative results, including cognitive therapy, ${ }^{63}$ family-voice reorientation ${ }^{64}$ and light therapy. ${ }^{65}$

Evidence is stronger for multicomponent interventions, ${ }^{24,66-68}$ likely reflecting that the development of delirium is multifactorial. The PADIS guideline found an odds ratio (OR) of 0.59 (95\% Cl 0.39-0.88) for reduced incidence of delirium with use of multicomponent bundles. ${ }^{57}$ The ABCDEF bundle is an operationalized framework of these guidelines; its components include pain management, trials of spontaneous awakening, choice of analgesia and sedation, monitoring and management of delirium, early mobilization, and family engagement. ${ }^{24}$ Principles of the ABCDEF bundle overlap with the demedicalization and patient-centred principles of the multicomponent interventions typically used in ACE units (outlined in Table 1 ). In a large, prospective, multicentre cohort study of more than 15000 patients, use of the bundle resulted in a dose-dependent reduction in delirium incidence (OR $0.60,95 \% \mathrm{Cl} 0.49-0.72$ ), coma, use of physical restraint, ICU readmission, and ICU and hospital mortality. ${ }^{24}$ Future studies should focus on implemen- tation and knowledge translation strategies; implementation resources are available online (www.icudelirium.org/medical -professionals/overview).

Antipsychotic use for the prevention of delirium is not recommended, ${ }^{57}$ given a Cochrane meta-analysis ${ }^{50}$ and large subsequent RCT of more than 1700 patients that showed no benefit over placebo. ${ }^{69}$ Dexmedetomidine may be preferentially considered for sedation in patients at high risk for delirium who require sedation for other indications. Although the PADIS guideline recommends against the use of dexmedetomidine for the prevention of delirium, ${ }^{57} 2$ more recent systematic reviews and meta-analyses suggest it is associated with reduced incidence of delirium. . $^{7071}$

Most evidence supporting the use of multicomponent bundles is related to prevention of delirium, but they are also recommended for its treatment, as their potential benefits outweigh the risks. ${ }^{24,57}$ Antipsychotics are not effective, with the Modifying the Impact of ICU-Associated Neurological Dysfunction-USA (MIND USA) multicentre RCT of 1789 patients finding no difference in effect between haloperidol, ziprasidone and placebo when measuring duration of delirium. ${ }^{54}$ The PADIS guideline supports use of dexmedetomidine when delirium-associated agitation precludes weaning or extubation, ${ }^{57}$ based on a single, lowquality RCT. ${ }^{72}$ The effectiveness of dexmedetomidine in delirium without agitation remains unclear, and dose reduction is suggested in those older than 65 years, owing to higher rates of bradycardia and hypotension. ${ }^{73}$

When symptoms of delirium such as hallucinations, anxiety or agitation cause psychological or physical harm to patients or pose risks to health care workers, antipsychotic treatment may be required. If so, it is best to follow the geriatric principle of "start low and go slow," and prescribe on a short-term and asneeded basis to avoid unintentional use after discharge from the ICU or hospital. A prospective observational cohort study found that $24 \%$ of patients treated for delirium with an atypical antipsychotic medication were discharged from hospital on these medications. ${ }^{74}$ Such discharge prescriptions are likely unintentional, but prescribing inertia may lead to their continued use.

\section{What post-ICU complications should physicians anticipate in older adults who survive critical illness?}

As medical and technological capabilities have improved, ICUassociated mortality has declined and most older adults survive critical illness; among ICU survivors older than 80 years, longterm mortality rates at 1,2 and 3 years after hospital discharge are comparable with age- and sex-matched general population mortality rates. ${ }^{75}$ One prospective study of 3920 patients with a mean age of 84 years from 22 countries found an ICU survival rate of $72.5 \%$, with a 30 -day survival rate of $61.2 \% .^{34}$ However, surviving critical illness may lead to long-term ICU-associated morbidity and functional decline, which are important outcomes to anticipate and manage proactively in the post-ICU period.

The prevalence of post-intensive care syndrome (PICS) in adults is unclear, but is believed to affect between $25 \%$ and $55 \%$ or 
more of ICU survivors. ${ }^{76,77}$ The syndrome encompasses a heterogeneous group of new or worsening cognitive, physical or mental health impairments ${ }^{78}$ (Figure 3), which can include posttraumatic stress disorder (PTSD) (44\% at $6 \mathrm{mo}^{79}$ ), impairment in instrumental activities of daily living, ${ }^{80}$ depression ( $34 \%$ at $6 \mathrm{mo}^{81}$ ), and cognitive impairment ( $34 \%$ at $12 \mathrm{mo}^{82}$ ). Given the scope of impairments, patients with PICS may need higher levels of care or informal caregiver support after hospital discharge. Post-intensive care syndrome-Family (PICS-F) is a similar grouping of outcomes in family members of ICU survivors, and includes new or worsening PTSD, depression, complicated grief or anxiety. ${ }^{83}$

Management of PICS after ICU discharge is an area of evolving knowledge. Most patients discharged from the hospital experience inadequate specialist follow-up and rehabilitation, polypharmacy, and fragmented care. ${ }^{84}$ Several systematic reviews have examined various post-ICU follow-up interventions; ${ }^{85-88}$ however, the results are difficult to interpret, given low-certainty evidence and heterogeneity in the populations, interventions, settings (inpatient v. outpatient) and outcome measures. We identified 5 controlled studies in which the intervention group had a mean age of more than 65 years. ${ }^{89-93}$ No studies provided subgroup analysis by degree of frailty, a major limitation given the evidence that pre-existing frailty substantially affects outcomes. Further studies on the management of older ICU survivors in the post-ICU period are needed, with a priori subgroup stratification by degree of frailty. Despite these limitations, some findings can be applied to older ICU survivors.

A large, population-based cohort study in Taiwan of more than 15000 sepsis survivors with a mean age of 69.4 years found that physical rehabilitation in the 90 days after ICU discharge resulted in $8 \%$ decreased 1-year mortality (hazard ratio [HR] 0.92, 95\% Cl 0.880.96 ) and 5.6\% decreased 10-year mortality (HR 0.94, 95\% Cl 0.920.97). ${ }^{90}$ Mortality reduced in a dose-dependent fashion based on the number of rehabilitation sessions that participants received..$^{90}$

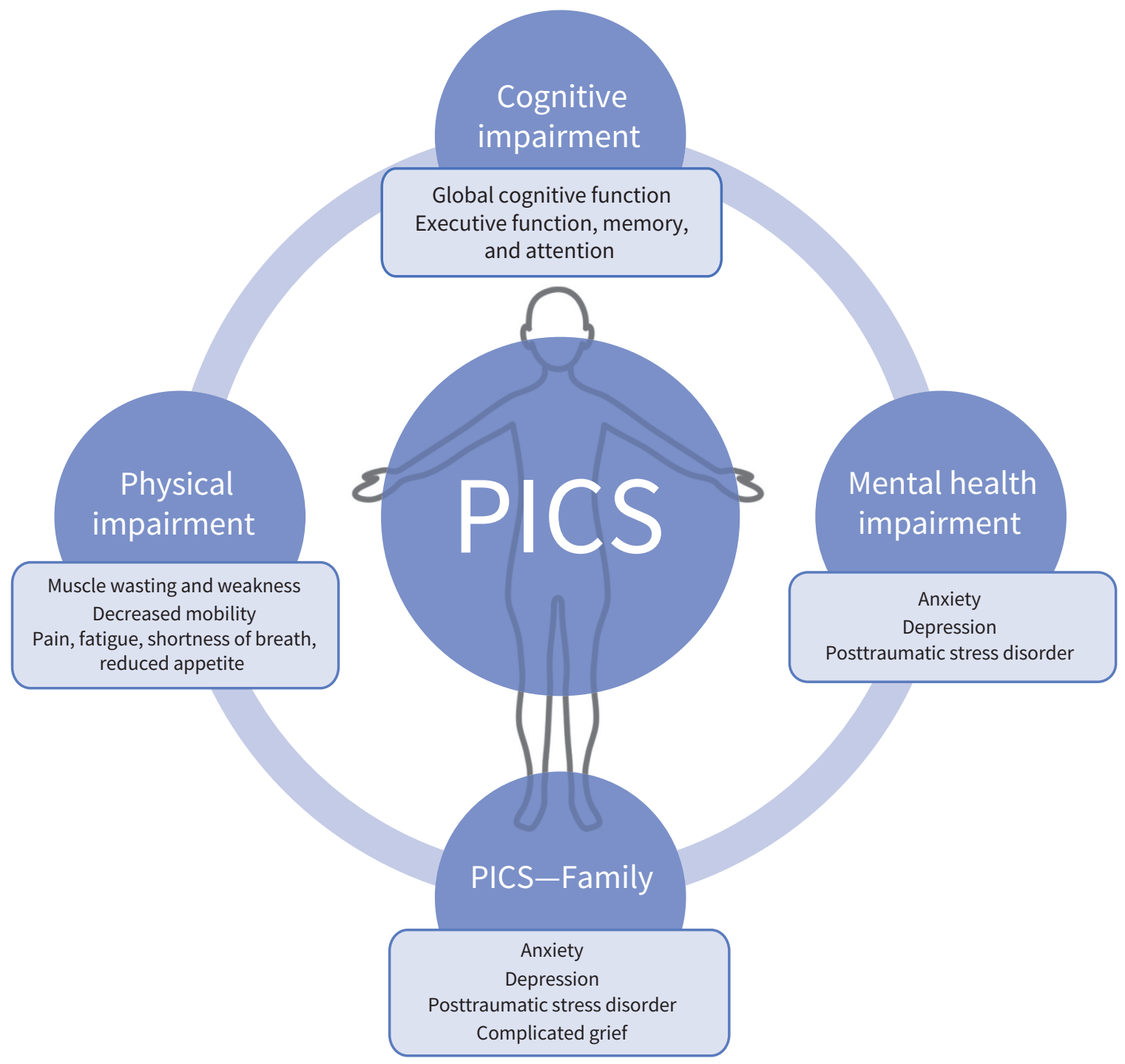

Figure 3: Components of post-intensive care syndrome (PICS). Survivors of the intensive care unit (ICU) may experience cognitive, physical and mental health impairments. Family members may also experience mental health impairments after the care of a loved one in the ICU. 
The benefit of physical therapy after critical illness was also shown in a recent systematic review of 16 RCTs and 10 observational studies of adult ICU survivors, which found that interventions for physical function improved depression and mental health-related quality of life..$^{85}$ Importantly, it appears benefits may be lost if the correct population is not targeted, which could partially explain why some rehabilitation studies have not shown the same benefit in other populations. ${ }^{94-96}$ For example, the study in Taiwan found that there was no survival benefit in patients with a duration of ICU stay or mechanical ventilation less than 7 days, or in those with few comorbidities (measured by a Charlson Comorbidity Index $\leq 2$ ), ${ }^{90}$ suggesting that patients most likely to benefit from physical rehabilitation are those who are less well at baseline or experience a prolonged critical illness and are thus at greater risk of muscle wasting and deconditioning. Determining what interventions work, for whom, and in what circumstances will help health teams avoid both under- and overuse of resources in patient-centred post-ICU care. A realist review (which uses a systematic approach to understand the mechanisms behind intervention outcomes) on post-ICU interventions is currently under way and will hopefully provide guidance for future post-ICU care pathways. ${ }^{97}$

Other potentially effective interventions in older adults include the use of an ICU diary ${ }^{92}$ and incorporation of ACE unit principles into post-ICU care. ${ }^{89}$ An ICU diary is a record kept by family and health care providers during a patient's ICU stay to fill in memory gaps, ${ }^{92}$ and in the general ICU population has been associated with reduced risk of depression and better quality of life in 2 systematic reviews. ${ }^{98,99}$ The ACE unit principles showed promise in 1 small RCT in France that, although underpowered, found a trend toward improved functional autonomy when older adults were admitted after ICU discharge to a geriatric ward using ACE unit principles, compared with routine care on a medical ward. ${ }^{89}$ Many hospital policies already support incorporation of geriatric principles into routine care for all older patients in the form of age-friendly care initiatives. ${ }^{100-103}$ The integration of ACE principles outlined in Table 1 may be considered for older ICU survivors admitted to medical or surgical wards, to prevent further hospital-acquired disability. Several studies using system and technological innovations to implement ACE principles are available. ${ }^{104-107}$

During a hospital stay or soon after hospital discharge, referral to geriatric medicine for cognitive impairment, geriatric psychiatry for mental health concerns, and physiatry for optimization of physical function may be helpful to address specific components of PICS, although referral strategies have not been directly studied. Other postdischarge management strategies, such as nurse-led ICU follow-up services, are not effective, according to current evidence..$^{86,87}$

\section{Conclusion}

Guidance on how best to care for critically ill older adults is limited by a lack of RCTs that specifically focus on older adults and lack of studies that stratify results by the degree of frailty. Despite these limitations, we have identified steps to improve care, including understanding pre-existing frailty as a prognostic tool in the ICU, the importance of nonpharmacologic multicomponent

\section{Box 2: Unanswered questions}

- What other interventions during or after admission to the intensive care unit (ICU) can prevent the incidence or worsening of frailty?

- How does frailty affect the success of interventions used to manage post-intensive care syndrome?

- Are collaborative care models using geriatric principles effective for the management of critically ill older adults during or after ICU admission, and what components are necessary for success?

interventions in delirium prevention and treatment, applying principles of geriatric medicine in routine ICU care, and an appreciation for the high prevalence of cognitive, physical and mental impairments after ICU admission. The involvement of geriatricians, who are experts in frailty, cognitive impairment and the care of older adults, may help intensivists and hospitalists focus on the acute nature of ICU and post-ICU care while the unique needs of older adults are addressed. Future research directions include geriatric collaborative care models in the ICU, implementation of geriatric principles in the post-ICU period, and the use of peri-ICU frailty assessments to create and monitor individualized treatment plans that address patients' overall health trajectories (see Box 2).

\section{References}

1. Care in Canadian ICUs: data tables. Ottawa: Canadian Institute for Health Information. Available: https://www.cihi.ca/en/care-in-canadian-icus-data -tables (accessed 2021 Aug. 18).

2. COVID 19 daily epidemiology update. Ottawa: Public Health Agency of Canada updated 2021 Sept. 3. Available: https://health-infobase.canada.ca/src/data/ covidLive/Epidemiological-summary-of-COVID-19-cases-in-Canada-Canada.ca.pdf (accessed 2021 Sept. 15).

3. Joyce MF, Reich JA. Critical care issues of the geriatric patient. Anesthesiol Clin 2015;33:551-61.

4. Flaatten $\mathrm{H}$, de Lange DW, Artigas $\mathrm{A}$, et al. The status of intensive care medicine research and a future agenda for very old patients in the ICU. Intensive Care Med 2017;43:1319-28.

5. Michels G, Sieber CC, Gernot M, et al. Geriatric intensive care: Consensus paper of DGIIN, DIVI, DGAI, DGGG, ÖGGG, ÖGIAIN, DGP, DGEM, DGD, DGNI, DGIM, DGKliPha and DGG [article in German]. Z Gerontol Geriatr 2019;52:440-56.

6. Conroy S, Parker S. Acute care for frail older people: time to get back to basics? Age Ageing 2014;43:448-9.

7. Brummel NE, Ferrante LE. Integrating geriatric principles into critical care medicine: the time is now. Ann Am Thorac Soc 2018;15:518-22.

8. Hao J-F, Cui H-M, Han J-M, et al. Tele-ICU: The way forward in geriatric care? Aging Clin Exp Res 2014;26:575-82.

9. Guidet B, Vallet H, Boddaert J, et al. Caring for the critically ill patients over 80 : a narrative review. Ann Intensive Care 2018;8:114.

10. Damluji AA, Forman DE, van Diepen S, et al.; American Heart Association Council on Clinical Cardiology and Council on Cardiovascular and Stroke Nursing. Older adults in the cardiac intensive care unit: factoring geriatric syndromes in the management, prognosis, and process of care: a scientific statement from the American Heart Association. Circulation 2020;141:e6-32.

11. Tardini F, Pinciroli R, Berra L. The intensive care unit: how to make this unfriendly environment more geriatric-friendly. Eur J Surg Oncol 2020;46:379-82.

12. Grigoryan KV, Javedan H, Rudolph JL. Orthogeriatric care models and outcomes in hip fracture patients: a systematic review and meta-analysis. $J$ Orthop Trauma 2014;28:e49-55.

13. Partridge JSL, Harari D, Martin FC, et al. Randomized clinical trial of comprehensive geriatric assessment and optimization in vascular surgery. Br J Surg 2017;104:679-87. 
14. Eagles D, Godwin B, Cheng W, et al. A systematic review and meta-analysis evaluating geriatric consultation on older trauma patients. J Trauma Acute Care Surg 2020;88:446-53.

15. Kalsi T, Babic-Illman G, Ross PJ, et al. The impact of comprehensive geriatric assessment interventions on tolerance to chemotherapy in older people. Br J Cancer 2015;112:1435-44.

16. Fox MT, Persaud M, Maimets I, et al. Effectiveness of acute geriatric unit care using acute care for elders components: a systematic review and meta-analysis. J Am Geriatr Soc 2012;60:2237-45.

17. O'Mahony D, O'Sullivan D, Byrne S, et al. STOPP/START criteria for potentially inappropriate prescribing in older people: version 2. Age Ageing 2015;44:213-8.

18. 2019 American Geriatrics Society Beers Criteria Updated Expert Panel. American Geriatrics Society 2019 updated AGS Beers Criteria for potentially inappropriate medication use in older adults. J Am Geriatr Soc 2019;67:674-94.

19. Counsell SR, Holder CM, Liebenauer LL, et al. Effects of a multicomponent intervention on functional outcomes and process of care in hospitalized older patients: a randomized controlled trial of Acute Care for Elders (ACE) in a community hospital. J Am Geriatr Soc 2000;48:1572-81.

20. Palmer RM. The acute care for elders unit model of care. Geriatrics (Basel) 2018;3:59.

21. Landefeld CS, Palmer RM, Kresevic DM, et al. A randomized trial of care in a hospital medical unit especially designed to improve the functional outcomes of acutely ill older patients. N Engl J Med 1995;332:1338-44.

22. Barnes DE, Palmer RM, Kresevic DM, et al. Acute care for elders units produced shorter hospital lengths of stays at lower costs while maintaining patients' functional status. Health Aff (Millwood) 2012;31:1227-36.

23. Flood KL, Booth K, Vickers J. Acute Care for Elders (ACE) team model of care: a clinical overview. Geriatrics (Basel) 2018;3:50.

24. Pun BT, Balas MC, Barnes-Daly MA, et al. Caring for critically ill patients with the ABCEDEF Bundle: results of the ICU liberation collaborative in over 15,000 adults. Crit Care Med 2019;47:3-14

25. Katlic MR, Coleman J, Khan K, et al. Sinai abbreviated geriatric evaluation: development and validation of a practical test. Ann Surg 2019;269:177-83.

26. Davidson JE, Aslakson RA, Long AC, et al. Guidelines for family-centered care in the neonatal, pediatric, and adult ICU. Crit Care Med 2017;45:103-28.

27. Muscedere J, Waters B, Varambally A, et al. The impact of frailty on intensive care unit outcomes: a systematic review and meta-analysis. Intensive Care Med 2017;43:1105-22.

28. Rockwood K, Song X, Macknight C, et al. A global clinical measure of fitness and frailty in elderly people. CMAJ 2005;173:489-95.

29. McDermid RC, Stelfox HT, Bagshaw SM. Frailty in the critically ill: a novel concept. Crit Care 2011;15:301.

30. Negm AM, Kennedy CC, Thabane L, et al. Management of frailty: a systematic review and meta-analysis of randomized controlled trials. J Am Med Dir Assoc 2019;20:1190-8

31. Darvall JN, Bellomo R, Bailey M, et al. Frailty and outcomes from pneumonia in critical illness: a population-based cohort study. Br J Anaesth 2020;125:730-8.

32. Flaatten H, De Lange DW, Morandi A, et al.; VIP1 study group. The impact of frailty on ICU and 30-day mortality and the level of care in very elderly patients (> 80 years). Intensive Care Med 2017;43:1820-8.

33. De Geer L, Fredrikson M, Tibblin AO. Frailty predicts 30-day mortality in intensive care patients: a prospective prediction study. Eur J Anaesthesiol 2020;37: 1058-65.

34. Guidet B, de Lange DW, Boumendil A, et al.; VIP1 study group. he contribution of frailty, cognition, activity of daily life and comorbidities on outcome in acutely admitted patients over 80 years in European ICUs; the VIP2 study. Intensive Care Med 2020;46:57-69.

35. De Biasio JC, Mittel AM, Mueller AL, et al. Frailty in critical care medicine: a review. Anesth Analg 2020;130:1462-73.

36. Heyland DK, Garland A, Bagshaw S, et al. Recovery after critical illness in patients aged 80 years or older: a multi-center prospective observational cohort study. Intensive Care Med 2015;41:1911-20.

37. Brummel NE, Bell SP, Girard TD, et al. Frailty and subsequent disability and mortality among patients with critical illness. Am J Respir Crit Care Med 2017;196:64-72.

38. Hendin A, Tanuseputro P, Mclsaac D, et al. Frailty is associated with decreased time spent at home after critical illness: a population-based study. $J$ Intensive Care Med 2021;36:937-44.

39. Ferrante LE, Pisani MA, Murphy T, et al. The association of frailty with post-ICU disability, nursing home admission, and mortality. Chest 2018;153:1378-86.
40. Bagshaw SM, Stelfox HT, McDermid RC, et al. Association between frailty and short-and long-term outcomes among critically ill patients: a multicentre prospective cohort study. CMAJ 2014;186:E95-102.

41. Fried LP, Tangen CM, Walston J, et al.; Cardiovascular Health Study Collaborative Research Group. Frailty in older adults: evidence for a phenotype. J Gerontol A Biol Sci Med Sci 2001;56:M146-56.

42. Buta BJ, Walston JD, Godino JG, et al. Frailty assessment instruments: systematic characterization of the uses and contexts of highly-cited instruments. Ageing Res Rev 2016;26:53-61.

43. Pugh RJ, Battle CE, Thorpe C, et al. Reliability of frailty assessment in the critically ill: a multicenter prospective observational study. Anaesthesia 2019;74:758-64

44. Pugh RJ, Ellison A, Pye K, et al. Feasibility and reliability of frailty assessment in the critically ill: a systematic review. Crit Care 2018;22:49.

45. Shears M, Takaoka A, Rochwerg B, et al.; Canadian Critical Care Trials Group. Assessing frailty in the intensive care unit: a reliability and validity study. $J$ Crit Care 2018;45:197-203.

46. Falvey JR, Ferrante LE. Frailty assessment in the ICU: translation to "real-world" clinical practice. Anaesthesia 2019;74:700-3.

47. Rolfson DB, Majumdar SR, Tsuyuki RT, et al. Validity and reliability of the Edmonton Frail Scale. Age Ageing 2006;35:526-9.

48. Rockwood K, Theou O. Using the Clinical Frailty Scale in allocating scarce health care resources. Can Geriatr J 2020;23:210-5.

49. Theou O, Pérez-Zepeda MU, van der Valk AM, et al. A classification tree to assist with routine scoring of the Clinical Frailty Scale. Age Ageing 2021;50:1406-11.

50. Herling SF, Greve IE, Vasilevskis EE, et al. Interventions for preventing intensive care unit delirium in adults. Cochrane Database Syst Rev 2018;11:CD009783.

51. Salluh JIF, Wang H, Schneider EB, et al. Outcome of delirium in critically ill patients: systematic review and meta-analysis. BMJ 2015;350:h2538.

52. Garpestad E, Devlin JW. Polypharmacy and delirium in critically ill older adults; recognition and prevention. Clin Geriatr Med 2017;33:189-203.

53. Mehta S, Cook D, Devlin JW, et al. SLEAP Investigators; Canadian Critical Care Trials Group. Prevalence, risk factors, and outcomes of delirium in mechanically ventilated adults. Crit Care Med 2015;43:557-66.

54. Girard TD, Exline MC, Carson SS, et al.; MIND-USA Investigators. Haloperidol and Ziprasidone for treatment of delirium in critical illness. N Engl J Med 2018;379: 2506-16.

55. Pandharipande PP, Ely EW, Arora RC, et al. The intensive care delirium research agenda: a multinational, interprofessional perspective. Intensive Care Med 2017;43:1329-39.

56. Diagnostic and statistical manual of mental disorders: DSM-5. 5th ed. Washington (DC): American Psychiatric Association; 2013.

57. Devlin JW, Skrobik Y, Gélinas C, et al. Clinical practice guidelines for the prevention and management of pain, agitation/sedation, delirium, immobility, and sleep disruption in adult patients in the ICU. Crit Care Med 2018;46:e825-73.

58. Pandharipande P, Shintani A, Peterson J, et al. Lorazepam is an independent risk factor for transitioning to delirium in intensive care unit patients. Anesthesiology 2006;104:21-6.

59. Zaal IJ, Devlin JW, Hazelbag M, et al. Benzodiazepine-associated delirium in critically ill adults. Intensive Care Med 2015;41:2130-7.

60. Neto AS, Nassar AP Jr, Cardoso SO, et al. Delirium screening in critically ill patients: a systematic review and meta-analysis. Crit Care Med 2012;40:1946-51.

61. Bergeron N, Dubois MJ, Dumont M, et al. Intensive care delirium screening checklist: evaluation of a new screening tool. Intensive Care Med 2001;27:859-64.

62. Litton E, Carnegie V, Elliott R, et al. The efficacy of earplugs as a sleep hygiene strategy for reducing delirium in the ICU: a systematic review and metaanalysis. Crit Care Med 2016;44:992-9.

63. Brummel NE, Girard TD, Ely EW, et al. Feasibility and safety of early combined cognitive and physical therapy for critically ill medical and surgical patients: the Activity and Cognitive Therapy in ICU (ACT-ICU) trial. Intensive Care Med 2014;40:370-9.

64. Munro CL, Cairns P, Ji M, et al. Delirium prevention in critically ill adults through an automated reorientation intervention: a pilot randomized controlled trial. Heart Lung 2017;46:234-8.

65. Simons KS, Laheij RJF, van den Boogaard M, et al. Dynamic light application therapy to reduce the incidence and duration of delirium in intensive-care patients: a randomized controlled trial. Lancet Respir Med 2016;4:194-202.

66. Foster J, Kelly M. A pilot study to test the feasibility of a nonpharmacologic intervention for the prevention of delirium in the medical intensive care unit. Clin Nurse Spec 2013;27:231-8. 
67. Moon K-J, Lee S-M. The effects of a tailored intensive care unit delirium prevention protocol: a randomized controlled trial. Int J Nurs Stud 2015;52:1423-32.

68. Rivosecchi RM, Kane-Gill SL, Svec S, et al. The implementation of a nonpharmacologic protocol to prevent intensive care delirium. J Crit Care 2016;31: 206-11.

69. van den Boogaard M, Slooter AJC, Brüggemann RJM, et al. Effect of haloperidol on survival among critically ill adults with a high risk of delirium: the REDUCE randomized clinical trial. JAMA 2018;319:680-90.

70. Ng KT, Shubash CJ, Chong JS. The effect of dexmedetomidine on delirium and agitation in patients in intensive care: systematic review and meta-analysis with trial sequential analysis. Anaesthesia 2019;74:380-92.

71. Pereira JV, Sanjanwala RM, Mohammed MK, et al. Dexmedetomidine versus propofol sedation in reducing delirium among older adults in the ICU: a systematic review and meta-analysis. Eur J Anaesthesiol 2020;37:121-31.

72. Reade MC, Eastwood GM, Bellomo R, et al. Effect of Dexmedetomidine added to standard care on ventilator-free time in patients with agitated delirium: a randomized clinical trial. JAMA 2016;315:1460-8.

73. Product monograph: ${ }^{\text {Pr }}$ dexmedeTOMidine Hydrochloride for injection. Boucherville (QC): Sandoz Canada Inc.; revised 2020 Mar. 24. Available: https://pdf.hres.ca/dpd_ pm/00056114.PDF (accessed 2020 Oct. 17).

74. Tomichek JE, Stollings JL, Pandharipande PP, et al. Antipsychotic prescribing patterns during and after critical illness: a prospective cohort study. Crit Care 2016;20:378.

75. Atramont A, Lindecker-Cournil V, Rudant J, et al. Association of age with shortterm and long-term mortality among patients discharged from intensive care units in France. JAMA Netw Open 2019;2:e193215.

76. Ohtake PJ, Lee AC, Scott JC, et al. Physical impairments associated with post-intensive care syndrome: systematic review based on the World Health Organization's international classification of functioning, disability and health framework. Phys Ther 2018;98:631-45.

77. Marra A, Pandharipande P, Girard T, et al. Co-occurrence of Post-Intensive Care Syndrome problems among 406 survivors of critical illness. Crit Care Med 2018;46:1392-1401.

78. Needham DM, Davidson J, Cohen $\mathrm{H}$, et al. Improving long-term outcomes after discharge from intensive care unit: report from a stakeholders' conference. Crit Care Med 2012;40:502-9.

79. Parker AM, Sricharoenchai T, Raparla S, et al. Posttraumatic stress disorder in critical illness survivors: a metaanalysis. Crit Care Med 2015;43:1121-9.

80. Hopkins RO, Suchyta MR, Kamdar BB, et al. Instrumental activities of daily living after critical illness: a systematic review. Ann Am Thorac Soc 2017;14:1332-43.

81. Rabiee A, Nikayin S, Hashem MD, et al. Depressive symptoms after critical illness: a systematic review and meta-analysis. Crit Care Med 2016;44:1744-53.

82. Pandharipande PP, Girard TD, Jackson JC, et al. Long-term cognitive impairment following critical illness. N Engl J Med 2013;369:1306-16.

83. Cameron JI, Chu LM, Matte A, et al. One-year outcomes in caregivers of critically ill patients. N Engl J Med 2016;374:1831-41.

84. Brown SM, Bose S, Banner-Goodspeed V, et al.; Addressing Post Intensive Care Syndrome 01 (APICS-01) study team. Approaches to addressing post-intensive care syndrome among intensive care unit survivors: a narrative review. Ann Am Thorac Soc 2019;16:947-56.

85. Rosa RG, Ferreira GE, Viola TW, et al. Effects of post-ICU follow-up on subject outcomes: a systematic review and meta-analysis. J Crit Care 2019;52:115-25.

86. Jensen JF, Thomsen T, Overgaard D, et al. Impact of follow-up consultations for ICU survivors on post-ICU syndrome: a systematic review and meta-analysis. Intensive Care Med 2015;41:763-75.

87. Schofield-Robinson OJ, Lewis SR, Smith AF, et al. Follow-up services for improving long-term outcomes in intensive care unit (ICU) survivors. Cochrane Database Syst Rev 2018;11:CD012701.

88. Mehlhorn J, Freytag A, Schmidt K, et al. Rehabilitation interventions for post intensive care syndrome: a systematic review. Crit Care Med 2014;42:1263-71.

89. Somme D, Andrieux N, Guérot E, et al. Loss of autonomy among elderly patients after a stay in a medical intensive care unit (ICU): a randomized study of the benefit of transfer to a geriatric ward. Arch Gerontol Geriatr 2010;50:e36-40.

90. Chao P-w, Shih C-J, Lee Y-J, et al. Association of postdischarge rehabilitation with mortality in intensive care unit survivors of sepsis. Am J Respir Crit Care Med 2014;190:1003-11.

91. Salisbury LG, Merriweather JL, Walsh TS. The development and feasibility of a ward-based physiotherapy and nutritional rehabilitation package for people experiencing critical illness. Clin Rehabil 2010;24:489-500.
92. Garrouste-Orgeas M, Coquet I, Périer A, et al. Impact of an intensive care unit diary on psychological distress in patients and relatives. Crit Care Med 2012;40:2033-40.

93. Jensen JF, Egerod I, Bestle MH, et al. A recovery program to improve quality of life, sense of coherence and psychological health in ICU survivors: a multicenter randomized controlled trial, the RAPIT study. Intensive Care Med 2016;42:1733-43.

94. Cuthbertson BH, Rattray J, Campbell MK, et al.; PRaCTICaL study group. The PRaCTICaL study of nurse led, intensive care follow-up programmes for improving long term outcomes from critical illness: a pragmatic randomized controlled trial. BMJ 2009;339:b3723.

95. Connolly B, Thompson A, Douiri A, et al. Exercise-based rehabilitation after hospital discharge for survivors of critical illness with intensive care unitacquired weakness: a pilot feasibility trial. J Crit Care 2015;30:589-98.

96. Elliott D, McKinley S, Alison J, et al. Health-related quality of life and physical recovery after a critical illness: a multi-centre randomized controlled trial of a home-based physical rehabilitation program. Crit Care 2011;15:R142.

97. Howard AF, Currie L, Bungay V, et al. Health solutions to improve post-intensive care outcomes: a realist review protocol. Syst Rev 2019;8:11.

98. Barreto BB, Luz M, de Oliveira Rios MN, et al. The impact of intensive care unit diaries on patients' and relatives' outcomes: a systematic review and metaanalysis. Crit Care 2019;23:411.

99. Mcllroy PA, King RS, Garrouste-Orgeas M, et al. The effect of ICU diaries on psychological outcomes and quality of life of survivors of critical illness and their relatives: a systematic review and meta-analysis. Crit Care Med 2019;47:273-9.

100. Fulmer T, Mate KS, Berman A. The age-friendly health system imperative. J Am Geriatr Soc 2018;66:22-4

101. Conroy S. Silver Book: quality care for older people with urgent and emergency care needs. London (UK): British Geriatrics Society; 2012.

102. Horgan S. Designing integrated care for older adults living with complex and chronic health needs: a scoping review. Provincial Geriatrics Leadership Office; 2020.

103. Age-friendly health systems: guide to using the $4 M$ s in the care of older adults. Bonston: Institute for Healthcare Improvement; 2020.

104. Malone ML, Volbrecht M, Stephenson J, et al. Acute Care for Elders (ACE) tracker and e-Geriatrician: methods to disseminate ACE concepts to hospitals with no geriatricians on staff. J Am Geriatr Soc 2010;58:161-7.

105. Booth KA, Simmons EE, Viles AF, et al. Improving geriatric care processes on two medical-surgical acute care units: a pilot study. J Healthc Qual 2019;41: 23-31.

106. Hung WW, Ross JS, Farber J, et al. Evaluation of the Mobile Acute Care of the Elderly (MACE) service. JAMA Intern Med 2013;173:990-6.

107. Farber JI, Korc-Grodzicki B, Du Q, et al. Operational and quality outcomes of a mobile acute care for the elderly service. J Hosp Med 2011;6:358-63.

\section{Competing interests: None declared.}

This article has been peer reviewed.

Affiliations: Divisions of Geriatric Medicine (Geen, Wang) and Critical Care Medicine (Rochwerg), Department of Medicine, and Department of Health Research Methods, Impact and Evidence (Rochwerg), McMaster University, Hamilton, Ont.

Contributors: Olivia Geen and Mimi Wang contributed to the conception and design of the work. Olivia Geen contributed to the acquisition of data. All of the authors contributed to the analysis and interpretation of data. Olivia Geen drafted the manuscript. Bram Rochwerg and Mimi Wang revised it critically for important intellectual content. All of the authors gave final approval of the version to be published and agreed to be accountable for all aspects of the work.

Content licence: This is an Open Access article distributed in accordance with the terms of the Creative Commons Attribution (CC BY-NCND 4.0) licence, which permits use, distribution and reproduction in any medium, provided that the original publication is properly cited, the use is noncommercial (i.e., research or educational use), and no modifications or adaptations are made. See: https://creativecommons.org/ licenses/by-nc-nd/4.0/

Correspondence to: Olivia Geen, olivia.geen@medportal.ca 